\title{
PANORAMA DE PROPRIEDADE INTELECTUAL, TRANSFERÊNCIA DE TECNOLOGIA E INOVAÇÃO DA QUÍMICA BRASILEIRA E A COMPARAÇÃO COM OS PAÍSES DO BRIC
}

\author{
Rubén Dario Sinisterra*, Marcelo Gomes Speziali, Pedro Pires Goulart Guimarães e Alice Machado da Silva \\ Departamento de Química, Universidade Federal de Minas Gerais, Avenida Antônio Carlos 6627, 31270-901 Belo Horizonte - MG, Brasil
}

Recebido em 4/7/13; aceito em 2/10/13; publicado na web em 24/10/13

\begin{abstract}
PANORAMA OF THE INTELLECTUAL PROPERTY, TECHNOLOGY TRANSFER AND INNOVATION FOR THE BRAZILIAN CHEMISTRY AND COMPARISON WITH THE BRIC COUNTRIES. Based on Science, Technology \& Innovation (ST\&I) indicators, Brazil is a competitive and interesting country from the point of view of technological foreign investment. However, it is still incipient with regard to national investments, production of technological knowledge, inbound mobility of scientists and technology transfer to the productive sector. Among many other factors, global patent production is considered as an important indicator of innovation. Likewise, the balance between revenue and expenses obtained through royalties and licensing fees of technologies is also critical in mapping the diffusion and absorption of knowledge. The understanding of intellectual property and its strategic management brings a significant advantage to the economic and technological development of nations, especially in the field of chemistry, which greatly contributes to biotechnology, new materials and microelectronics - three fundamental areas for innovation in developed countries. Therefore, this article aims to map out competencies in chemistry in Brazil and evaluate science, technology and innovation indicators in the country, comparing this dynamic to the one of other BRIC members (Russia, India and China). Chemistry is the fourth biggest field of interest in Brazil based on the number of researchers registered at the governmental platform for researchers, Plataforma Lattes/CNPq, and is preceded by education, medicine and agronomy. The majority of research groups are registered in the area of materials, followed by macromolecules and polymers, pharmaceutical products and basic materials chemistry. These groups represent approximately $77 \%$ of research groups analyzed, therefore, indicating a tendency in the country. The analyses of patents in different sub-areas of chemistry reveal that non-residents file most deposits in the country, a probable reflection of the low internal intellectual property culture. Pharmaceutics and Fine Chemistry are prominent areas in the country, in line with the global trend. Among BRIC countries, China has the highest number of patents and of requests for protection in international offices. On the other hand, Brazil has the lowest number of chemical patents published at USPTO, EPO and JPO. An analysis of the transfer of technology data indicates an increase in this activity in various sub-areas of chemistry in the country. Despite the great efforts made by the country to consolidate its national innovation system, more needs to be done to put Brazil in a competitive position. In a globalized world dominated by large players, Brazil needs a lot of progress on ownership and generation of chemistry technologies to strengthen its national sovereignty. It is essential to strengthen chemical research at all levels, from elementary school to university, as an inexhaustible source of knowledge and technology that, when properly protected, may generate real public achievement and social return.
\end{abstract}

Keywords: intellectual property; technology transfer; innovation.

\section{INTRODUÇÃO}

O constante fluxo da informação científica tradicional para a pesquisa tecnológica, como fonte de geração de inovação, faz da transferência de tecnologia e propriedade intelectual (PI) tópicos essenciais para a gestão do conhecimento. Em paralelo ao trabalho publicado em Química Nova - Química Sem Fronteiras, ${ }^{1}$ o presente artigo aborda o tema de PI como um novo desafio à comunidade científica, particularmente à comunidade de químicos brasileiros. Em uma análise ampla do contexto e da importância do tema PI em Química, não somente para o desenvolvimento tecnológico, mas também para inserção da política-científica brasileira nos grandes blocos econômicos produtores de conhecimento, buscamos qualificar a ciência e tecnologia num contexto glocal. O artigo propõe a gestão do conhecimento produzido baseado em um benchmarking internacional, considerando áreas químicas estratégicas para o Brasil e alguns pontos da política de CT\&I, além dos desafios apontados por Pinto e colaboradores. ${ }^{1}$ Aspectos de propriedade intelectual na área da química brasileira serão comparados com a dos países membros do bloco econômico Brasil, Rússia, Índia e China, denominados BRIC.

*e-mail: sinisterra@ufmg.br

\section{INOVAÇÃO DOS PAÍSES MEMBROS DO BRIC NO CONTEXTO GLOBAL}

Diversos estudos avaliam os fatores de produção de conhecimento, tecnologia, inovação e competitividade dos países. Dentre eles, o índice de inovação do relatório de competitividade mundial, publicado pela Organização Mundial da Propriedade Intelectual (OMPI) e o Instituto Insead (Escola de Negócios para o Mundo), merece destaque especial. Esse índice de inovação global leva em consideração fatores como: educação básica, educação universitária (ciências e engenharias), criação e impacto de conhecimento e tecnologia, produção de intangíveis criativos, além de infraestrutura e sofisticação de negócios e de mercado. ${ }^{2}$ Analisando a posição dos BRIC no ranking divulgado em 2012, a China lidera em 34 $4^{\circ}$, seguida da Rússia em $51^{\circ}$ e Brasil em $58^{\circ}$. A Índia aparece em $64^{\circ}$ lugar.

Segundo a análise dos países do BRIC divulgada nesse relatório, a distribuição de fortalezas e fraquezas da competitividade de inovação do Brasil segue uma tendência similar à da Rússia. Essas semelhanças são notadas em relação aos seguintes pilares analisados: instituições, infraestrutura e sofisticação de mercado e negócios. O Brasil e a China estão posicionados depois da Rússia em relação à formação de recursos humanos e pesquisa. O Brasil aparece em último lugar em produção de conhecimento e tecnologia e em segundo em relação à 
produção criativa. Apesar da posição obtida em relação à produção de conhecimento, o impacto das publicações brasileiras é o maior dentre os BRIC. Quando o número de publicações científicas é avaliado, o Brasil aparece em segundo lugar (juntamente com a Índia). ${ }^{3}$

Por outro lado, quando avaliada a eficiência de inovação, isto é, a relação entre os fatores de base na produção de inovação e os resultados obtidos, o Brasil sofreu a maior queda dentre os BRIC, passando a ocupar a 39a posição em 2012 (em 2011 aparecia em $10^{\circ}$ ). Dentre os indicadores que obtiveram menor nota estão: o número de patentes depositadas via Tratado de Cooperação em Matéria de patentes (PCT) com ao menos um inventor estrangeiro; o ambiente de negócios em geral; a educação de nível superior e finalmente a importação e exportação de produtos e serviços como percentagem do PIB. Estes dois últimos representam os subíndices nos quais o Brasil aparece nas piores colocações globais, $141^{\circ}$ e $139^{\circ}$, respectivamente. ${ }^{2}$ Esses dados demonstram a necessidade urgente de buscar alternativas para superar as fraquezas do sistema nacional de inovação.

O mercado da indústria química mundial evoluiu de USD 1 trilhão em 1970 para 4,12 trilhões em 2010, com previsão de crescimento para USD 6,5 trilhões em $2020 .{ }^{4}$ A indústria química brasileira está entre a $6^{\mathrm{a}}-7^{\mathrm{a}}$ do mundo, ${ }^{5}$ com geração de 5.956 empregos em 2011 (um crescimento de $22,1 \%$ em relação a 2010). No entanto, ela ainda atrai apenas $6 \%$ do número total de projetos de investimento estrangeiro direto (IED) do país ${ }^{6}$ e gerou um déficit de comércio exterior de quase USD 27 bilhões em 2010, importações de agroquímicos e fertilizantes. ${ }^{1}$

Segundo o Kotler, a situação dos clusters industriais (indústrias e empresas) é o principal fator que determina a competitividade de uma nação, e o sucesso da inovação dentro do cluster depende do aprender pela interação, ou seja, fazendo e usando. Analisando a formação dos principais clusters industriais em países desenvolvidos, destacam-se as seguintes áreas: biotecnologia, novos materiais e microeletrônica, áreas essas de uso intensivo da pesquisa em química - ciência central capaz de modificar a matéria e considerada pela OCDE uma área de alta e média tecnologia ${ }^{7}$ - fundamental para inovação de uma nação. ${ }^{8}$ De acordo com índices considerados por Kotler, o Brasil ainda possui um grande desafio para a formação de clusters competitivos. No entanto, existem outras áreas em que o Brasil aparece entre os maiores produtores e exportadores, principalmente no que tange a produtos relacionados ao agronegócio, energias renováveis e biocombustíveis. Esse cenário é consequência de esforços conjuntos e continuados de políticas públicas e do setor industrial, que favoreceram a atuação de empresas brasileiras no mercado interno e no cenário internacional, como por exemplo a Petrobrás. ${ }^{9}$ O Brasil ainda apresenta outros exemplos bem sucedidos de destaque internacional, como os clusters na área aeronáutica, com a participação da multinacional Embraer, e na área de produção e exportação de alimentos, com a Embrapa. ${ }^{10}$

\section{PRODUÇÃO DO CONHECIMENTO E FORMAÇÃO DE RECURSOS HUMANOS}

A produção de artigos científicos brasileiros indexados pela Thomson/ISI e Scopus passou de 8.414 artigos em 1996 para 46.933 em 2011. ${ }^{11}$ Um grande volume de conhecimento foi produzido na área de química em 2010, considerando o número de artigos científicos publicados internacionalmente. A China, por exemplo, apresentou um crescimento exponencial, com 25.000 artigos publicados em um ano (índice médio de impacto - IMI, de 0,6), seguida pela Alemanha com uma produção mais ou menos estável em torno de 10.000 (IMI de 1,4), França com 7.000 (IMI de 1,3), Espanha e Coréia do Sul com 5000 (IMI de 1,3 e 0,8, respectivamente), Canadá com 4.000 (IMI de 1,3), Brasil com 2.500 (IMI de 0,6) e Argentina com 1.000 (IMI de 0,7). ${ }^{12,13}$ De acordo com um estudo da Thomson Reuters, a comunidade química brasileira está publicando dentro da média internacional para a área - 0,6. ${ }^{13} \mathrm{~A}$ avaliação nos períodos de 19982002 e 2003-2007 $7^{14}$ mostra que a química é a quarta área em número de publicações científicas do país e a terceira em relação à taxa de crescimento do número dessas publicações, ressaltando a importante contribuição e peso da área para o desenvolvimento científico do país. Essa produção científica está correlacionada à formação de recursos humanos em nível de doutorado e mestrado. Entre 1996 e 2008, foram titulados 3.671 doutores em química no Brasil, quantia mais significativa que outras áreas das ciências exatas e da terra. ${ }^{15} \mathrm{O}$ número total de mestres no período de 1996-2009 na área da química foi de 6.980 , ficando em segunda posição depois da área de ciências da computação. ${ }^{16}$

Essa formação maciça de recursos humanos e a crescente produção científica são resultado dos 55 programas de pós-graduação acadêmicos existentes em química e dois mestrados profissionais no Brasil. Na última avaliação da CAPES do triênio 2007-2009 verifica-se a existência de 10 cursos de nível 6 e 7 (de inserção internacional) e 12 cursos de nível 5, 18 de nível 4 e 14 de nível 3. ${ }^{17}$

Em 2010 existiam 1.036 grupos de pesquisa registrados na Plataforma Lattes do CNPq na área da química, ou seja, 3,8\% de todos os grupos de pesquisa nas mais diversas áreas do conhecimento. ${ }^{18}$ Este número coloca a química como o quarto grande grupo de pesquisadores cadastrados, após educação, medicina e agronomia. Os grupos de pesquisa em química concentram-se fundamentalmente nos estados de São Paulo, Minas Gerais, Paraná, Rio Grande do Sul e Rio de Janeiro, respectivamente (Figura 1). Esse resultado está de acordo com os dados da indústria química brasileira, englobando 1.029 fábricas espalhadas pelo país. Dessas, $60 \%$ atua na área petroquímica, estando concentradas em quatro polos localizados em São Paulo, Bahia, Rio Grande do Sul e Rio de Janeiro, coincidindo em grande parte com a concentração dos grupos de pesquisa do país. ${ }^{19}$

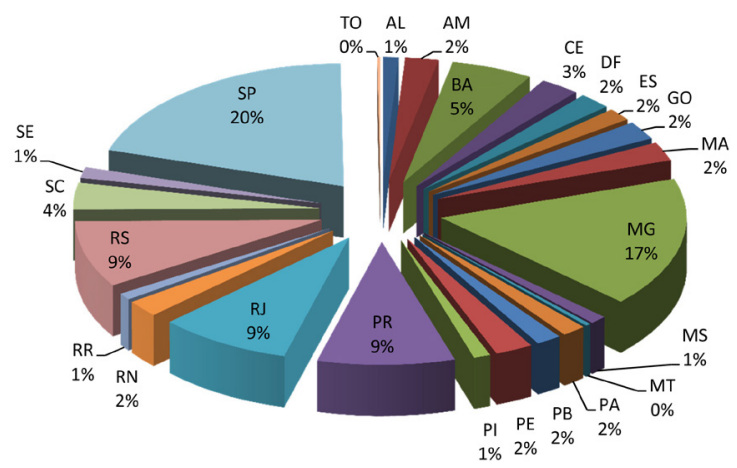

Figura 1. Distribuição do somatório das áreas estratégicas em química pelo Brasil

Visando obter um cenário mais específico da química no Brasil, o setor tecnológico da química foi dividido em 14 subáreas, como proposto pelo Instituto Fraunhofer na Alemanha para a OMPI com o propósito de harmonizar os dados sobre tecnologias entre diferentes países e torná-los comparativos. ${ }^{20}$ Essa divisão em subáreas utiliza a classificação internacional de patentes (IPC), bastante similar às classificações normalmente utilizadas para diferentes setores tecnológicos, mas não idêntica. Portanto, foi necessário fazer um panorama das subáreas considerando palavras-chave correlacionadas às definidas pelo Instituto Fraunhofer e pelos pesquisadores do CNPq. Analisando a distribuição das competências químicas verifica-se uma distribuição heterogênea das áreas de pesquisa em cada estado (Figura 2).

O Brasil possui atualmente 333 grupos registrados no CNPq na área de materiais, 220 grupos na área de macromoléculas e polímeros, 150 grupos de produtos farmacêuticos e 106 grupos que trabalham 


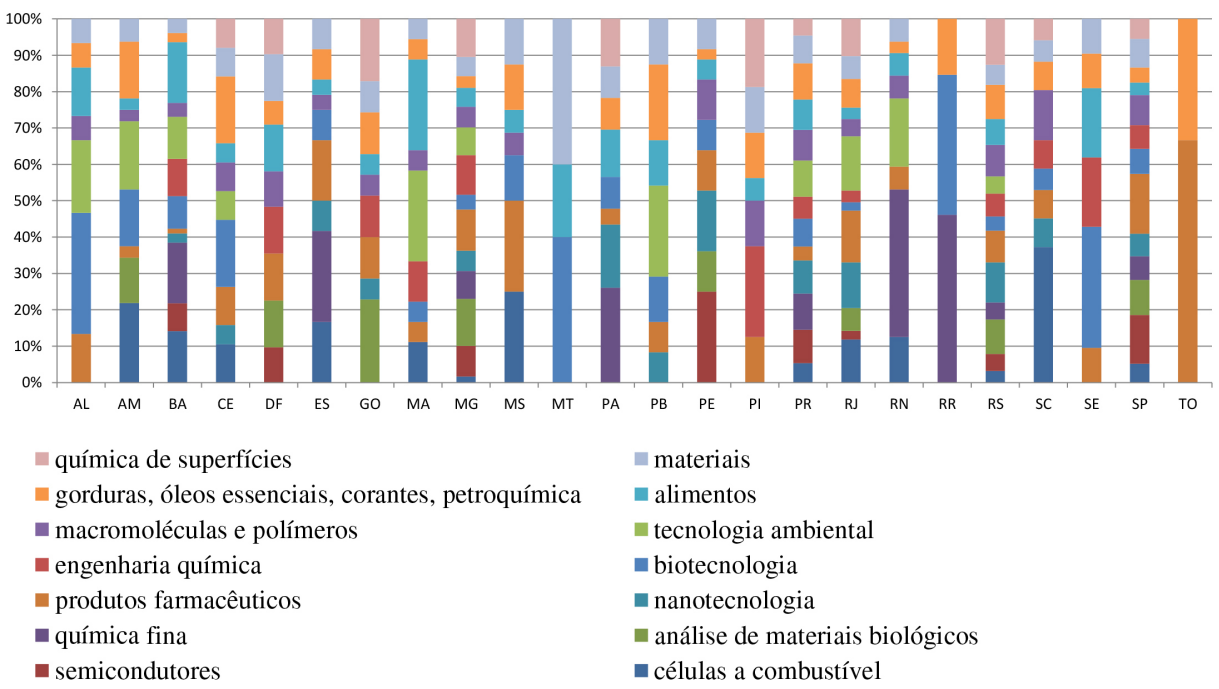

Figura 2. Distribuição das competências químicas por estado segundo as áreas consideradas pelo Instituto Fraunhofer

com materiais básicos da química, como algumas commodities, corantes e óleos essenciais. Essas quatro subdivisões representam aproximadamente $77 \%$ dos grupos de pesquisa analisados, indicando certa tendência no país. Embora as áreas de semicondutores, nanotecnologia e tecnologias ambientais sejam áreas portadoras de futuro, ${ }^{21}$ possuem representação de menos de $5 \%$ em relação ao total de grupos cadastrados na área da química. Estabelecendo um ajuste fino do censo da química brasileira, dentro das subdivisões propostas pelo Instituto Fraunhofer, foi possível recuperar 265 grupos de pesquisa em bioprospecção e química de produtos naturais cadastrados no CNPq. Este é um número bastante significativo se compararmos com a área mais expressiva - materiais (com 333 grupos).

\section{ALGUNS INDICADORES DE INOVAÇÃO EM QUÍMICA NO BRASIL}

Indicadores de patentes são frequentemente utilizados para mapear aspectos da inovação e do progresso tecnológico de países, regiões ou mesmo áreas tecnológicas. Embora o número de pedidos de patentes publicados não seja um indicador isolado da inovação de um país (uma vez que essa tecnologia deve ser transferida para o mercado para que resulte em inovação), países inovadores e reconhecidos como potências mundiais possuem um número expressivo de pedidos de patentes. O número de patentes é levado em consideração em diversas análises de inovação mundial, como o Índice de Inovação Global (INSEAD/OMPI) e o Índice de Desenvolvimento Humano (IDH).

No presente estudo, o desenvolvimento do setor da química brasileiro foi analisado a partir da prospecção das patentes nessa área no período de 1998 a 2011 - posteriormente à promulgação da Lei de Propriedade Industrial no Brasil, Lei No. 9279 de 1996. Os resultados foram analisados em relação a depósitos realizados por residentes e não residentes nas diferentes subáreas da química - a partir do número de pedido de patentes publicados. A prospecção foi realizada utilizando o mecanismo de busca da OMPI. ${ }^{22}$ As subáreas da química foram selecionadas de acordo com a metodologia do próprio banco de dados da OMPI e já utilizada no presente estudo para a classificação dos grupos de pesquisa da química do Brasil. ${ }^{20}$

Dentre os membros do BRIC, a China é o país que possui o maior número de depósito de patentes, ${ }^{23} \mathrm{o}$ que também ocorre na área da química (Figura 3). O aumento contínuo das publicações de patentes em química na China contrasta com os dados do Brasil, Rússia e Índia, em que se verificam flutuações significativas ao longo dos anos. Como consequência, a diferença entre o número de patentes de química publicadas na China e no Brasil, que era apenas de quatro vezes em 2008, passa a ser de 18 vezes em 2011.

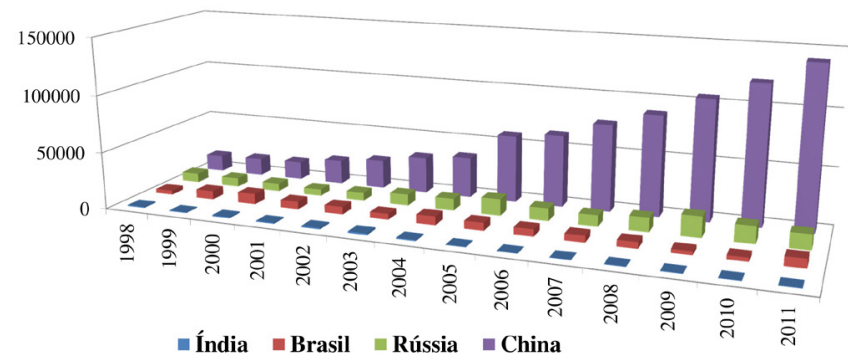

Figura 3. Pedidos de patente da área de química publicados nos países do BRIC

Analisando o cenário da química brasileira em maior detalhe, verifica-se que o número de pedidos de patente de não residentes é significativamente superior ao de residentes em todas as subáreas analisadas (Figura 4). As subáreas com maior número de patentes depositadas no Brasil são a Farmacêutica e a Química Fina. Essas são também as que apresentam a maior disparidade entre o número de depósitos realizados por residentes e por não residentes. Esses dados mostram o interesse estrangeiro em áreas consideradas estratégicas para a nação brasileira e reforçam a necessidade de políticas públicas urgentes e sustentáveis para o fortalecimento das competências nacionais nessas áreas. Já as subáreas de semicondutores e microestruturas apresentaram o menor número de pedidos publicados no país. Esse resultado é provavelmente um reflexo da falta dessas atividades econômicas Brasil, consequência de políticas públicas protecionistas

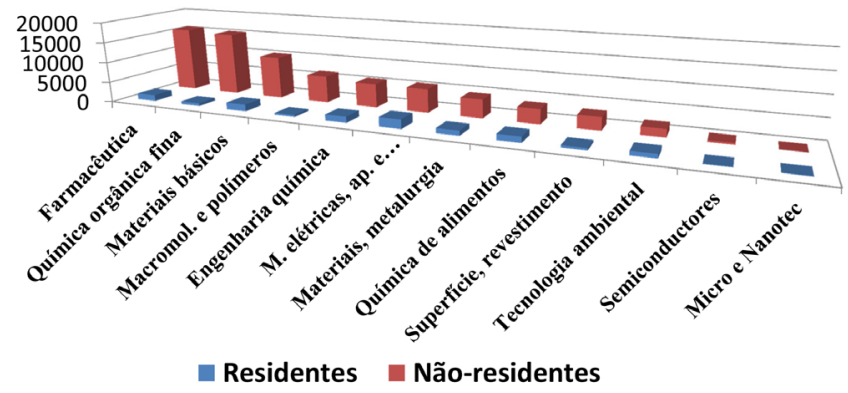

Figura 4. Pedidos de patente de residentes e não residentes publicados por área da química no período de 1998-2011 
da década de 80 , que acabaram por gerar um hiato científico e tecnológico no país. ${ }^{24} \mathrm{~A}$ tendência semelhante observada nos pedidos publicados na área de Nanotecnologia sugere que a subárea ainda é incipiente no país, embora venha crescendo na última década.

As subáreas de maior desempenho nacional (em relação ao número de pedidos de patentes publicados) são: (i) máquinas elétricas, aparelhos e energia, (ii) química de materiais básicos, (iii) farmacêutica e (iv) engenharia química. ${ }^{25} \mathrm{~A}$ área (i) possui um alto número de depósitos por residentes. No entanto, ela engloba tecnologias que transitam em outras áreas além da química. Vale ressaltar que energia é uma área especialmente estratégica para o país: $31 \%$ dos investidores esperam que o Brasil seja líder no setor de energia até $2020{ }^{6}$ Por outro lado, um desafio importante na área de energia está relacionado ao domínio praticamente total do mercado de terras raras pela China (97\%), uma vez que essas são fundamentais para aplicações contemporâneas em geradores eólicos, luminóforos, baterias, etc. ${ }^{26}$

Em todas as subáreas analisadas existe uma acentuada disparidade entre os depósitos de patentes de residentes no Brasil e os depósitos de residentes na China. Os números do Brasil correspondem a, no máximo, $10 \%$ do total de pedidos de residentes na China. ${ }^{25}$ Mesmo quando o número de pedidos de patentes em química é avaliado per capita, o Brasil ainda apresenta um número 4,3 vezes menor que o da China. Portanto, os dados demonstram que os nossos esforços internos, embora significativos, ainda estão muito aquém dos obtidos pelos chineses.

Visando analisar a atratividade internacional do Brasil na área da química, o número de pedidos de patentes de não residentes depositados no país foi avaliado e comparado ao da China (Figura 5). Nota-se que esse investimento internacional em depósitos de patentes era similar no Brasil e na China no ano 2000. Todavia, a configuração tornou-se muito distinta a partir dessa data. Enquanto houve uma flutuação do número de pedidos de patentes de não residentes publicados no Brasil a partir de 2000, os dados da China mostram um aumento contínuo desde 1998. Entre 2005 e 2010, por exemplo, o interesse estrangeiro na China aumentou, enquanto no Brasil houve uma redução gradativa de pedidos publicados por não residentes.

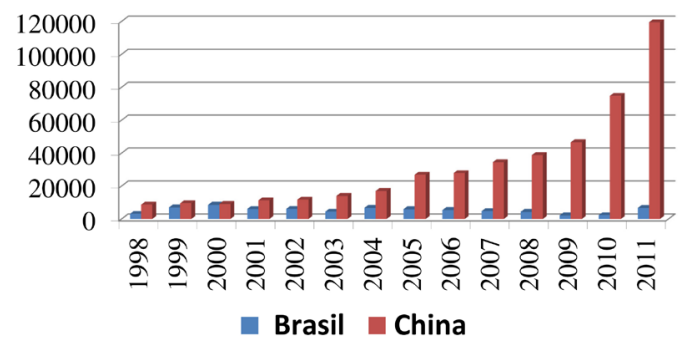

Figura 5. Pedidos de patente de não residentes na área de química publicados no Brasil e China entre 1998-2011

Levando em consideração que o número de patentes depositadas não reflete necessariamente a importância econômica das mesmas, análises mais refinadas são normalmente utilizadas para obter um cenário mais claro dos resultados de P\&D. Um parâmetro frequentemente empregado como indicador de patentes de alto valor é o depósito nos três maiores escritórios de patente do mundo, o USPTO (Estados Unidos), o European Patent Office (EPO, Europa) e o Japan Patent Office (JPO, Japão). Este raciocínio baseia-se na premissa que os depositantes só assumem os altos custos de se buscar proteção em outros países se considerarem que os esforços valerão a pena. ${ }^{27}$

No presente estudo não foi possível avaliar o número de patentes tríades, ou seja, depositadas por residentes brasileiros tanto no USPTO, quanto no EPO e JPO. No entanto, foi avaliado o número de depósitos na área da química realizados individualmente nesses escritórios, em uma tentativa de se medir os esforços nesse setor para depositar pedidos de patentes nos mercados de maior interesse mundial. Os resultados obtidos mostram que dentre os países do BRIC os chineses são os que mais têm solicitado proteção nos respectivos escritórios internacionais (Figura 6), seguidos, curiosamente, pelos indianos, cujo número de pedidos de patente de química no próprio país é significativamente inferior aos outros países do BRIC (Figura 3). Essa estratégia da Índia em depositar patentes nos países da tríade é também observada em uma análise global, compreendendo todos os setores tecnológicos, ${ }^{27}$ sugerindo que os indianos buscam a proteção de suas invenções visando a exploração comercial em outros países. Entre os países do BRIC, o Brasil é que menos possui patentes de química publicadas no USPTO, EPO e JPO (Figura 6). ${ }^{25}$ Essa posição do Brasil em relação aos BRIC também foi observada na análise global de patentes triádicas para os setores tecnológicos como um todo. ${ }^{27}$

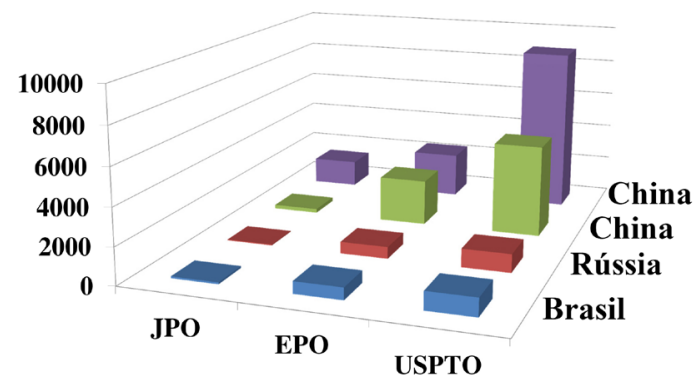

Figura 6. Pedidos de patente de química de países do BRIC publicados no JPO, EPO e USPTO na área química no período de 1998-2011

Quando se avalia a preferência dos norte-americanos para o depósito de patentes nos países do BRIC, nota-se que a Índia é o país de menor interesse, embora seja o segundo país do BRIC que mais protege na Europa, Estados Unidos e Japão (Figura 7). Já o Brasil é o segundo BRIC de interesse dos norte-americanos, depois da China. ${ }^{25}$ Os norte-americanos, assim como outros não residentes (Figura 4) possuem maior número de pedidos no Brasil na subárea farmacêutica, seguida pela química orgânica fina e química de materiais básicos.

Apesar da grande atratividade do mercado Chinês na área da química, evidenciada na Figura 7, é possível perceber que o cenário já foi diferente no início do século 21, quando o Brasil era o país de maior interesse dos norte-americanos, tendo sido ultrapassado pela China a partir de 2001 (Figura 7). A diferença entre os países tornou-se cada vez mais acentuada, demonstrando claramente uma mudança estratégia dos norte-americanos. Além do mais, pode ser verificada uma queda acentuada no número de pedidos publicados no Brasil, principalmente em 2009 e 2010. Curiosamente, os números mais expressivos de pedidos de norte-americanos na China foram publicados em 2009, 2010 e 2011, época de plena crise mundial.

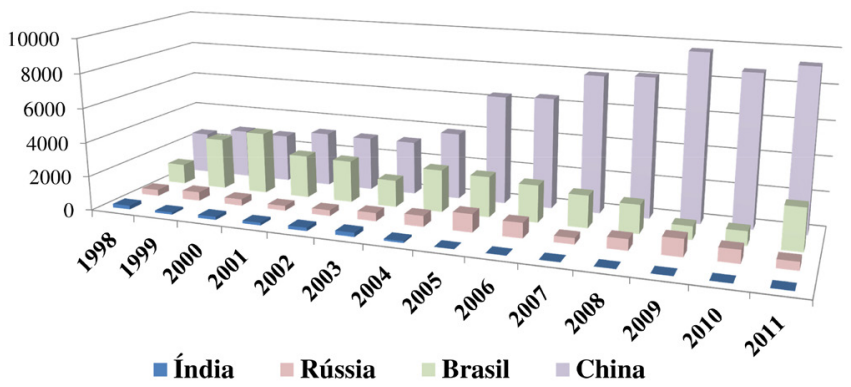

Figura 7. Pedidos de patente originários dos Estados Unidos, publicados nos países do BRIC no período de 1998-2011 
Vale mencionar que o gasto interno bruto da China em P\&D (GERD, do inglês Gross Expenditure in $R \& D$ ) vem crescendo em ritmo acelerado desde 1998, estando atualmente próximo ao recomendado pela Comissão Europeia: $2 \%$ do PIB. ${ }^{23}$ Já a relação GERD/ PIB no Brasil tem permanecido relativamente estável. No entanto, o gasto não empresarial com P\&D no Brasil é de $0,59 \%$ do PIB, porcentagem maior que a de outros membros do BRIC e próxima à média da União Europeia. ${ }^{28}$ Já os gastos privados com o GERD só são maiores que o da Índia (dentre os BRIC). Dessa maneira, o menor desempenho brasileiro frente à China em relação aos dados de patentes apresentados pode ser um reflexo da concentração de conhecimento em Institutos de Ciência e Tecnologia e do baixo índice de investimento em PD\&I por empresas brasileiras.

\section{Transferência de tecnologia}

Os dados sobre os processos de transferência de tecnologia são um termômetro do grau de desenvolvimento tecnológico de um país, possuindo relação direta com a intensidade de geração de tecnologia e inovação, como consequência de uma política consolidada de gestão estratégica de proteção, valoração, comercialização de tecnologia, know-how, know-why e know-what dos países.

Entre 2002 e 2005, o Brasil apresentou um aumento das exportações de produtos de média tecnologia - como produtos primários agrícolas e agroindustriais - de aproximadamente USD 37 bilhões e um crescimento das importações em cerca de USD 10,6 bilhões. ${ }^{29}$ Em contraste, o déficit da balança comercial brasileira para produtos químicos passou de USD 1,2 bilhões em 1990 para USD 26,6 bilhões em 2011. ${ }^{6}$

Dados recentes publicados pelo INPI (Instituto Nacional de Propriedade Industrial) indicam que, comparando os anos 2000 e 2011, o número de certificados de averbação de exploração de patentes aumentou de 34 para 57 e o de fornecimento de tecnologia passou de 214 para 279. Por outro lado, os serviços de assistência técnica diminuíram, passando de 1077 para $877 .{ }^{30}$ Quando avaliado o número de remessas ao exterior para transferência de tecnologia verifica-se um aumento de 1.127 remessas em 2000 para 3.026 em $2011 .^{31}$

O número de certificados de averbação em subáreas da química, segundo a Classificação Nacional de Atividades Econômicas - CNAEIBGE, quando comparados os anos 2000 e 2011, passou de 32 para 43 no setor de fabricação de borrachas e plásticos; 70 para 15 na fabricação de celulose e papel e produtos de papel; 72 para $63 \mathrm{em}$ relação à fabricação de produtos alimentícios e bebidas; 66 para 206 no setor de fabricação de coque e refino de petróleo; 41 para 26 na fabricação de minerais não metálicos e 129 para 164 na fabricação de produtos químicos. ${ }^{31}$

Os principais países fornecedores de tecnologia para o Brasil em 2011 foram: Estados Unidos com 483 averbações, demais países 299, Alemanha 248, Japão 173, França 129, Reino Unido 94, Itália 65, Suíça 48, Canadá 38 e Espanha 34. Foram averbados por residentes, no mesmo ano, 142 certificados. ${ }^{30}$ Vale a pena salientar o relato de Bittencourt sobre alguns casos de sucesso de transferências de tecnologias de Universidades Brasileiras, na área de química, para a indústria nacional. ${ }^{32}$

\section{Cultura da propriedade intelectual}

Como discutido por Galembeck em 2012, professores e alunos frequentemente leem artigos, mas raramente leem patentes, ignorando assim conhecimento de fronteira, essencial para uma ciência original e competitiva. ${ }^{33}$ Vale ressaltar que esse é também um denominador na indústria nacional brasileira, demonstrando a necessidade de mudança de cultura nas universidades e nas empresas brasileiras com relação ao uso estratégico de propriedade intelectual.

O compromisso com a inovação vem sendo introduzido no sistema acadêmico e de pesquisa brasileiro. No entanto, a mudança na cultura das universidades é um processo gradual. Essas mudanças começam com a criação dos núcleos de inovação tecnológica nas universidades e centros de pesquisa, aliado ao tradicional ponto triplo de apoio da universidade: pesquisa, ensino e extensão. Cursos de propriedade intelectual, empreendedorismo, campeonatos de ideias inovadoras, planos de negócios, novos processos e produtos no mercado brasileiro oriundos da pesquisa começam a fazer parte do ambiente acadêmico. Essas atividades precisam ser continuadas e consolidadas na formação de nossos alunos de graduação e pós-graduação. A formação básica em gestão estratégica de propriedade intelectual, empreendedorismo e geração de novos negócios possibilitará o adensamento do processo de inovação em todas as áreas, especialmente na química. A formação básica em propriedade intelectual durante a graduação poderá contribuir para a capacitação de recursos humanos para os Núcleos de Inovação Tecnológica (NIT), escritórios de patentes e indústrias. No caso dos NIT, esse aporte de mão de obra especializada colabora direta e indiretamente com a profissionalização da produção de patentes nas universidades. Speziali e colaboradores discutem em seu recente artigo uma desmistificação do assunto de patentes nas universidades, demonstrando a importância de se ter profissionais das áreas científicas e tecnológicas atuando intensivamente nesse contexto. ${ }^{34} \mathrm{~A}$ burocratização do ensino público nas universidades federais e a extensa carga de trabalho administrativo enfrentada por professores dificulta enormemente a inserção destes num sistema de inovação mais aprimorado. Embora algumas iniciativas despontem com sucesso em algumas universidades, esse fenômeno deve ser incorporado por todas as instituições de ensino. A comunidade acadêmica deve ter em mente que as oportunidades de colocação no mercado profissional não se restringem apenas a laboratórios de pesquisa e que a ciência básica e a tecnologia aplicada caminham juntas.

\section{CONSIDERAÇÕES FINAIS}

O panorama nacional da propriedade intelectual, transferência de tecnologia e inovação da química brasileira é muito dinâmico, complexo e envolve processos sofisticados de formação de recursos humanos, pesquisa, produção de artigos científicos, patentes e sua gestão estratégica. Adicionalmente verifica-se que apesar do grande esforço realizado pelo país para a consolidação do sistema nacional de inovação, este ainda é insuficiente para colocar o país em uma posição competitiva. Em um mundo globalizado dominado pelos grandes players, o Brasil ainda precisa avançar muito na apropriação e geração de tecnologias na área da química de forma a fortalecer a soberania nacional. Acreditamos que o processo de excelência e aprofundamento da pesquisa em química deve ser fortalecido e consolidado em todos os níveis, desde o ensino fundamental até a pós-graduação, como fonte inesgotável de novos conhecimentos e tecnologias. Quando protegidos devidamente, esses poderão se converter em reais conquistas públicas e retorno social.

Vislumbram-se assim novos desafios e reflexões para a comunidade científica, industrial e governamental brasileira, em particular da química, área central e estratégica para o desenvolvimento do Brasil: 1. Faz-se necessário promover na formação dos químicos contemporâneos a cultura de excelência acadêmica, relevância científica, proteção do conhecimento, transferência de tecnologia e geração de spin-offs, para que se possa alcançar um processo de inovação mais dinâmico e eficaz; 
2. Fomentar e consolidar a cultura da gestão estratégica da propriedade intelectual na academia e nas empresas, de forma a permitir uma maior geração de novos processos e produtos que gerem emprego e renda no país;

3. Fortalecer e dar continuidade às políticas públicas para aumentar a multidisciplinaridade e interdisciplinaridade das ciências, bem como a cooperação nacional e internacional com foco em áreas estratégicas como nanotecnologia, biotecnologia, energia, química verde, química ambiental, materiais e uso sustentável da biodiversidade;

4. Buscar o ponto de equilíbrio entre a proteção e a divulgação aberta do conhecimento gerado pela universidade, bases fundamentais para a geração de riqueza para o país com fundamental papel na difusão da ciência e tecnologia;

5. Estabelecer um sistema organizacional da química brasileira que permita mapear, classificar, priorizar e valorizar o know-how e o capital humano na área da química, tornando mais dinâmico o processo de transferência de tecnologia e geração de novos empreendimentos contemporâneos, competitivos internacionalmente, de forma a adensar a cadeia produtiva da química e a permitir a redução do desequilíbrio da balança comercial brasileira.

\section{AGRADECIMENTOS}

Os autores gostariam de agradecer à Diretoria e o Conselho Consultivo da Sociedade Brasileira de Química e a comissão integrada pelos Professores A. C. Pinto, C. Zucco, F. Galembeck, P. C. Vieira e J. B. de Andrade pelo convite e à Prof ${ }^{\text {a }}$. M. E. Cortés da FO-UFMG pela leitura crítica e sugestões.

\section{REFERÊNCIAS}

1. Pinto, A. C.; Zucco, C.; Galembeck, F.; Andrade, J. B. d.; Vieira, P. C.; Quim. Nova 2012, 35, 2092.

2. Dutta, S.; The Global Innovation Index 2012: Stronger Innovation Linkages for Global Growth, as co-publishers and their Knowledge Partners 2012, INSEAD and the World Intellectual Property Organization (WIPO): France, 2012.

3. Anônimo em OECD Science, Technology and Industry Scoreboard 2011; OECD: 2011.

4. Tuncak, B.; Driving Innovation: How stronger laws help bring safer chemicals to market, CIEL: Washington, 2013.

5. http://www.ilaese.org.br/wp-content/uploads/2013/03/a-industriaquim\%C3\%ADca-no-Brail-em-2013-por-Eric-Gil.pdf, acessada em Novembro 2013.

6. Ernst \& Young; A hora de investir - Pesquisa de atratividade Ernst \& Young - 2012; Ernst \& Young Terco; 2012.

7. Anônimo; The Knowledge based economy, OECD: Paris, 1996.

8. Kotler, P.; Jatusripitak, S.; Maesincee, S.; O marketing das nações: uma abordagem estratégica para construir as riquezas nacionais, Futura: São Paulo, 1997.

9. http://www.economist.com/node/16952914, acessada em Agosto 2013; http://www.economist.com/node/14845197, acessada em Agosto 2013.

10. http://www.economist.com/node/16886442, acessada em Agosto 2013.
11. http://www.mct.gov.br/index.php/content/view/5710/Numero_de_artigos_brasileiros_da_America_Latina_e_do_mundo_publicados_em_periodicos_cientificos_indexados_pela_ThomsonISI_e_Scopus.html, acessada em 18 de junho 2013.

12. http://www.rdmag.com/digital-editions/2012/12/2013-r-d-magazineglobal-funding-forecast, acessada em Junho 2013.

13. Cruz, C. H. d. B.; Alguns dados sobre a pesquisa em Química no Brasil, FAPESP, 2011.

14. Thomson Reuters; The Grown-Up BRIC: Innovation \& Brand Expansion in Brazil; Thomson Reuters; Washington; 2012.

15. Anônimo; Doutores 2010: Estudos da demografia da base técnicocientífica brasileira, Centro de Gestão e Estudos Estratégicos: Brasília, 2010

16. Anônimo; Mestres 2012: Estudos da demografia da base técnicocientífica brasileira, Centro de Gestão e Estudos Estratégicos: Brasília, 2012.

17. Dupont, J.; Dias, L. C.; Relatório de Avaliação 2007-2009, CAPES, 2010

18. http://dgp.cnpq.br/buscaoperacional/, acessada em Junho 2013; http:// dgp.cnpq.br /censos/sumula_estatistica/2010/grupos/index_grupo.htm, acessada em 20 de junho 2013.

19. Moreira, C.; Fernandes, E.; Gomes, G. L.; Dvorsak, P.; Heil, T. B. B.; Bastos, V. D.; Potencial de Investimento no Setor Petroquímico Brasileiro 2007-2010, BNDES, 2007.

20. Schmoch, U.; Concept of a Technology Classification for Country Comparisons, Fraunhofer Institute for Systems and Innovation Research and WIPO, 2008

21. Anônimo; Estratégia nacional de ciência e tecnologia e inovação 2012 2015, Ministério da Ciência, Tecnologia e Inovação: Brasília, 2011.

22. http://ipstatsdb.wipo.org/ipstatv2/ipstats/patentsSearch, acessada Junho 2013

23. Adams, J.; Pendlebury, D.; Stembridge, B.; Thomsom Reuters; Building Bricks - Exploring the global research and innovation impact of Brazil, Russia, India, China and South Korea; 2013.

24. Biazzi, M. R. d.; Contribuição para o desenho organizacional de instituição pública brasileira: estudo de caso no setor de semicondutores., USP, São Paulo, 2012.

25. Speziali, M. G.; Sinisterra, R. D.; Goulart, P. P.; Silva, A. M. d.; trabalho não publicado; 2013.

26. Serra, O. A.; J. Braz. Chem. Soc. 2011, 22, 809

27. Anônimo Em Factbook 2011-2012; OECD: 2011, Cap. Patents.

28. Anônimo; Relatório UNESCO sobre ciência 2010, 2010.

29. Brentani, R. R.; Cruz, C. H. d. B.; Suzigan, W.; Furtado, J. E. d. M. P.; Garcia, R. d. C. Em Indicadores de Ciência, Tecnologia e Inovação em São Paulo 2010; FAPESP: São Paulo, 2011, Cap. 6.

30. http://www.inpi.gov.br/images/docs/dicig_certificadoaverbao_catcontratual.pdf, acessada Junho 2013.

31. http://www.inpi.gov.br/images/docs/dicig_remessaexterior.pdf, acessada em Junho 2013.

32. Andrade, J. B. d.; Lopes, W. A.; Parcerias Estratégicas 2011, 26, 385

33. Galembeck, F.; Pesquisa Fapesp; Ciência e inovação; FAPESP; São Paulo; 2012.

34. Speziali, M. G.; Guimarães, P. P. G.; Sinisterra, R. D.; Quim. Nova 2012 35,1700 